\title{
Verification of the International Society of Urological Pathology recommendations in Japanese patients with clear cell renal cell carcinoma
}

\author{
HAKUSHI KIM ${ }^{1}$, CHIE INOMOTO ${ }^{2}$, TAKATO UCHIDA ${ }^{1}$, HIROYUKI FURUYA ${ }^{3}$, TOMOYOSHI KOMIYAMA ${ }^{4}$, \\ HIROSHI KAJIWARA ${ }^{2}$, HIROYUKI KOBAYASHI ${ }^{4}$, NAOYA NAKAMURA ${ }^{2}$ and AKIRA MIYAJIMA ${ }^{1}$ \\ Departments of ${ }^{1}$ Urology, ${ }^{2}$ Pathology, ${ }^{3}$ Preventive Medicine and ${ }^{4}$ Clinical Pharmacology, \\ Tokai University School of Medicine, Isehara, Kanagawa 259-1193, Japan
}

Received December 12, 2017; Accepted February 21, 2018

DOI: $10.3892 /$ ijo.2018.4294

\begin{abstract}
The aim of the present study was to evaluate the validity of potential prognostic parameters of clearcell renal cell carcinoma (ccRCC) recommended by the 2012 International Society of Urological Pathology (ISUP) Consensus Conference in the Japanese population. We reviewed 406 Japanese patients with localized or locally advanced ccRCC who underwent curative surgery during 2004-2014 at Tokai University Hospital (Isehara, Japan) and were followed up for $>2$ years after surgery. A single pathologist reviewed all the histological slides. Morphological subtype and pathological T stage were reassigned according to the 2016 World Health Organization and TNM classifications. Sarcomatoid differentiation (SD), rhabdoid differentiation (RD), tumor necrosis (TN) and microvascular invasion (MVI) were assessed according to the 2012 ISUP recommendations. Nuclear grade was reclassified according to both the Fuhrman and the ISUP grading systems. Recurrence-free survival (RFS) and cancer-specific survival (CSS) were assessed through univariate and multivariate analyses. According to the Fuhrman grading system (group Fuhrman), TN and MVI were independent risk factors for postoperative recurrence in the multivariate analysis using the Cox proportional hazards model. According to the ISUP grading system (group ISUP), TN and MVI were independent risk factors for postoperative recurrence. In group Fuhrman, age, Fuhrman grade and TN were independent risk factors for CSS. In group ISUP, age, ISUP grade, and TN were independent risk factors for CSS. Furthermore, the group that was upgraded from Fuhrman grade 2 to ISUP grade 3 exhibited
\end{abstract}

Correspondence to: Dr Hakushi Kim, Department of Urology, Tokai University School of Medicine, Shimokasuya 143, Isehara, Kanagawa 259-1193, Japan

E-mail: qblong888@gmail.com

Key words: renal cell carcinoma, clear cell renal cell carcinoma, International Society of Urological Pathology, coagulative tumor necrosis poorer CSS compared with the group that was reclassified from Fuhrman grade 2 to ISUP grade 2 (non-upgraded). Regardless of the nuclear grade, TN remained an independent predictor of RFS and CSS. To the best of our knowledge, this is the first report to prove the correlation between the 2012 ISUP recommendations and clinical outcomes in a Japanese ccRCC cohort. TN and upgrading to ISUP grade 3 were found to be potentially useful independent indicators of postoperative prognosis.

\section{Introduction}

Kidney cancer is the ninth and fourteenth most common cancer in men and women, respectively, and the sixteenth most common cause of cancer-related mortality worldwide. In Japan, the estimated age-standardized incidence of kidney cancer among both sexes was 5.3 per 100,000 population (http:/gco.iarc.fr/today/online-analysis-map?mode=cancer\& mode_population $=$ continents $\&$ population $=900 \&$ sex $=0 \&$ cancer $=29 \&$ type $=0 \&$ statistic $=0 \&$ prevalence $=0 \&$ color_palette $=$ default \&projection=natural-earth) $(1,2)$. Renal cell carcinoma (RCC) is the most common type of adult epithelial kidney cancer (2). The 2016 World Health Organization (WHO) classification describes 13 distinct morphotypes (including unclassified ones) in RCC. Among those subtypes, clear cell RCC (ccRCC) is the most common type of renal parenchymal tumor, accounting for $63-83 \%$ of RCC cases, and its outcome is significantly poorer when compared with the outcome of other subtypes, such as papillary RCC or chromophobe RCC (3-5). The International Society of Urological Pathology (ISUP) 2012 Consensus Conference also reported new recommendations for classification. There was a strong consensus (98\%) that the main morphotypes of RCC have prognostic significance, and that the cancer-specific survival (CSS) rate of ccRCC is significantly lower compared with that of papillary or chromophobe RCC at comparable stages (6).

In addition to tumor morphotype, other pathological parameters were suggested as being potential prognostic factors at the 2012 ISUP Conference, including sarcomatoid differentiation (SD), rhabdoid differentiation (RD), tumor necrosis (TN), novel nuclear ISUP grade and microvascular 
invasion (MVI) (6). In the present study, we focused on TN, ISUP grade and MVI as potential prognostic factors. TN is often encountered in RCC and has been reported in 27-32\% of ccRCC cases $(7,8)$. The presence of TN has been correlated with not only high-risk clinicopathological parameters, but also poor disease-specific survival (9-13). The 2012 ISUP Conference recommended the use of the ISUP grading system rather than the Fuhrman grading system. The ISUP grading system for ccRCC is defined only by nucleolar prominence and has exhibited a stronger association with patient outcome compared with that exhibited by the Fuhrman grading system (14). MVI is controversial as a prognostic factor in some studies.

To date, there have been several reports on the assessment of the ISUP recommendations in Western countries; however, there are few reports from East Asia, and no reports on the Japanese population. As the Japanese are a homogeneous race, the validity of the research results in Western countries require verification in a Japanese cohort.

The aim of the present study was to review all pathological slides of localized RCC from Japanese patients who underwent radical surgery at our institution over the past 10 years, and reclassify them by morphotype, TN, ISUP grade and MVI, according to the consensus of the 2012 ISUP Conference and, subsequently, on the basis of these results, to identify strong predictive factors affecting recurrence-free survival (RFS) and CSS. To the best of our knowledge, this study is the first to report on a Japanese population with postoperative localized or locally advanced ccRCC assessed according to the 2012 ISUP recommendations.

\section{Materials and methods}

Patient selection. The postoperative prognostic and clinicopathological data were retrospectively analyzed in accordance with a protocol approved by Tokai University Institutional Review Board. Between January 2004 and December 2014, a total of 631 patients with localized or locally advanced RCC underwent radical or partial nephrectomy at the Department of Urology of Tokai University Hospital (Isehara, Japan). Patients with synchronous bilateral renal tumors or synchronous metastases (to lymph nodes or other organs) were excluded from the analysis. All pathological slides of the patients were revised on the basis of the 2016 WHO classification and the TNM system by a single pathologist (C.I.). Among all 631 tumors, 514 were confirmed as being of the morphological ccRCC type. Finally, 406 patients who could be observed for $>2$ years after surgery were included in the analysis. The median age of the 406 patients was 62 years (range, 27-85 years). The male:female ratio was $\sim 3: 1$. Radical nephrectomy was performed in 268 patients, and partial nephrectomy in 138 patients. The median postoperative follow-up period was 59 months (range, 3-137 months). A total of 48 patients had recurrent tumors during the follow-up period. The characteristics of the patients are summarized in Table I.

Pathological review. A single pathologist (C.I.) reviewed all tumors of the 631 patients and reassigned the tumors by histological subtype, pathological T stage, nuclear grade, TN, SD, RD and MVI. Histological subtype and pathological T stage
Table I. Clinicopathological characteristics of the 406 patients with ccRCC.

\begin{tabular}{lr} 
Characteristics & No \\
\hline Median age, years (range) & $62(27-85$ \\
Sex & \\
Male & 309 \\
Female & 97 \\
Side & \\
Left & 192 \\
Right & 214 \\
Nephrectomy type & \\
Radical & 268 \\
Partial & 138 \\
Median postoperative follow-up, & \\
months (range) & \\
Pathological T stage & \\
T1a & 272 \\
T1b & 76 \\
T2a & 12 \\
T2b & 3 \\
T3a & 16 \\
T3b & 26 \\
T4 & 1
\end{tabular}

Tumor size, median mm (range)

Fuhrman grade

1

2

4

ISUP grade

$1 \quad 4$

2227

32153

$4 \quad 22$

Microvascular invasion

Positive 77

Negative $\quad 329$

Tumor necrosis

Positive 43

Negative 363

Sarcomatoid differentiation

Positive 9

Negative 397

Rhabdoid differentiation

Positive 17

Negative $\quad 389$

ccRCC, clear cell renal cell carcinoma; ISUP, International Society of Urological Pathology.

were reassigned according to the 2016 WHO classification. TN, SD, RD, and MVI were assessed according to the 2012 


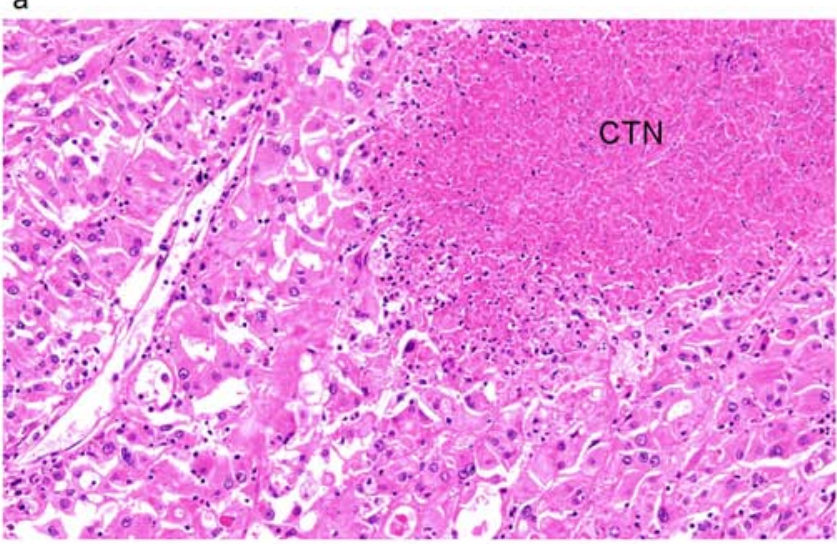

b

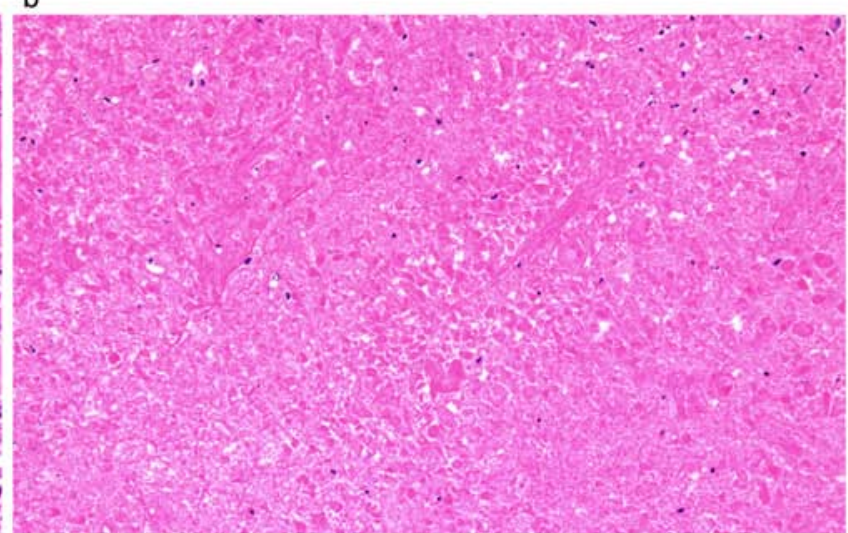

Figure 1. Photomicrograph of coagulative tumor necrosis. (a) Example of coagulative tumor necrosis (CTN) adjacent to eosinophilic tumor cells (H\&E staining; magnification, x20). (b) Histopathological slide showing ischemic necrosis, which should be distinguished from CTN (H\&E staining; magnification, x20). H\&E, hematoxylin and eosin.

a

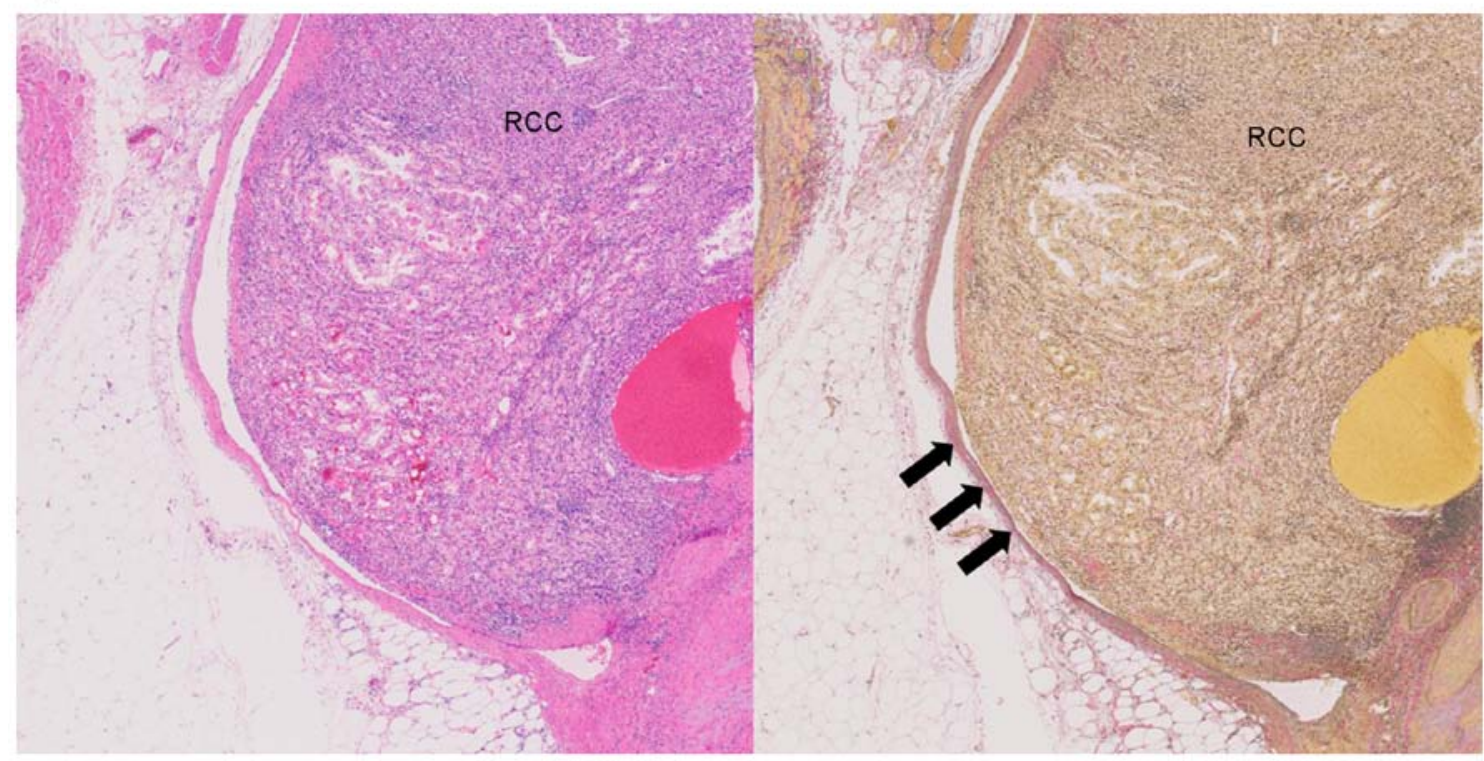

Figure 2. Photomicrograph of microvascular invasion. (a) Renal cell carcinoma (RCC) is seen protruding into the vessel (hematoxylin and eosin staining; magnification, x20). (b) The tumor cells broke through the vessel collagen wall and invaded into the vessel (arrows). Elastica Van Gieson staining; magnification, $\mathrm{x} 20$.

ISUP Consensus Conference recommendations (6). The presence of TN was defined as microscopic coagulative tumor necrosis in the tumor section (Fig. 1a). Fibrosis, hyalinization, hemorrhage and ischemic necrosis (Fig. 1b) within a tumor were distinguished from coagulative tumor necrosis to avoid misdiagnosis of tumor necrosis. MVI was defined as a lump of tumor cells inside a vessel lined by one or more layers of vascular endothelial cells. If the presence of endothelial cells made the image unclear, elastin staining was performed to identify the vessel wall (Fig. 2a and b). Nuclear grade was reassigned according to both the Fuhrman and ISUP grading systems. The group that was reclassified by the Fuhrman grading system was named group Fuhrman, and the group that was reclassified by the ISUP grading system was named group ISUP. Cases with questionable pathological diagnoses were reviewed by another pathologist (H.K.). If the two pathologists had different opinions regarding the diagnosis, they examined the slides together and consensus was reached through discussion. The pathologists were blinded to the clinical outcome. The pathological findings are summarized in Table I. The Fuhrman and ISUP grading systems are defined as in Table II.

Statistical analysis. The RFS interval was defined as the time from the day of surgery until detection of recurrence. The CSS interval was defined as the time from the day of surgery until death from RCC. Data from patients who remained alive without recurrence at the last evaluation or who died of other causes were censored. RFS and CSS for clinical and pathological factors were calculated according to the Kaplan-Meier method and compared with the log-rank test. Clinical and pathological factors were defined as follows: Age ( $\leq 62$ vs. $>62$ years), sex (male vs. female), pT stage ( $\leq$ pT2 vs. $\geq$ pT3), Fuhrman grade 
Table II. Fuhrman and ISUP grading systems.

Fuhrman grading system

ISUP grading system

\section{Grade 1}

Tumors were composed of cells with small $(\sim 10 \mu \mathrm{m})$ round uniform nuclei with inconspicuous or absent nucleoli

Grade 2

Tumor cells had larger $(\sim 15 \mu \mathrm{m})$ nuclei that exhibited irregularities in the outline and nucleoli when examined under high-power magnification $(\mathrm{x} 400)$

Grade 3

Tumor cells had even larger nuclei $(\sim 20 \mu \mathrm{m})$ with an obviously irregular outline and prominent large nucleoli

even at low-power magnification (x100)

Grade 4

Tumor cells exhibit characteristics similar to those of grade 3 tumors with the addition of bizarre, often multilobed nuclei and heavy chromatin clumps. These tumors often display areas of spindled-shaped cells resembling sarcomas

\section{Grade 1}

Nucleoli are inconspicuous or absent at a magnification of $\mathrm{x} 400$

Grade 2

Nucleoli are clearly visible at high-power magnification, but are not prominent

Grade 3

Nucleoli are prominent and are easily visualized at low-power magnification

Grade 4

Presence of tumor giant cells and/or marked nuclear pleomorphism and/or with rhabdoid or sarcomatoid differentiation

ISUP, International Society of Urological Pathology.

(1/2 vs. 3/4), ISUP grade (1/2 vs. 3/4), TN (absence or presence) and MVI (absence or presence). SD and RD were excluded, as these factors were included in one of the factors of grade 4 of the ISUP grading system. The median age of 62 years was used to separate younger from older patients. Multivariate analyses were performed using a Cox proportional hazards model. P-values of $<0.05$ were considered to indicate statistically significant difference. Clinical outcomes (RFS and CSS) were separately calculated in group Fuhrman and group ISUP. To discriminate the predictive accuracy for clinical outcomes between groups Fuhrman and ISUP, the concordance index (c-index) was used. A value of 1.0 represents perfect predictive models, and a value of 0.5 is equivalent by chance.

We also specifically evaluated the clinical outcomes for patients whose cancers were reclassified to a different grade by the ISUP grading system. All the statistical analyses were performed with JMP ${ }^{\circledR}$ version 12.0.1 (SAS Institute, Cary, NC, USA) and Stata 14 (StataCorp LP, College Station, TX, USA).

\section{Results}

Results of pathological review based on the 2016 WHO classification and the 2012 ISUP Consensus Conference. Table I shows the histopathological characteristics of all 406 patients with ccRCC reviewed on the basis of the 2016 WHO classification and the 2012 ISUP recommendations. The nuclear grade according to the Fuhrman grading system was 1 in 3 tumors, 2 in 343 tumors, 3 in 38 tumors, and 4 in 22 tumors. In the same population, the ISUP grade was 1 in 4 tumors, 2 in 227 tumors, 3 in 153 tumors, and 4 in 22 tumors. The number of cases whose nuclear grading differed between the Fuhrman and the ISUP grading systems are presented in Table III. The percentage of positivity of the adverse pathological characteristics of TN and MVI was 10.6 and $19.0 \%$, respectively.
Table III. Number of cases whose nuclear grading changed between the Fuhrman and ISUP systems.

\begin{tabular}{lrrrrr}
\hline & \multicolumn{5}{c}{ Fuhrman grade } \\
\cline { 2 - 6 } ISUP grade & 1 & 2 & 3 & 4 & Total \\
\hline 1 & 2 & 2 & 0 & 0 & 4 \\
2 & 1 & 224 & 2 & 0 & 227 \\
3 & 0 & 117 & 36 & 0 & 153 \\
4 & 0 & 0 & 0 & 22 & 22 \\
Total & 3 & 343 & 38 & 22 & 406 \\
\hline
\end{tabular}

ISUP, International Society of Urological Pathology.

Statistical analysis of the impact of clinicopathological factors on RFS and CSS. The 5-year RFS and CSS rates for all 406 patients with ccRCC estimated by the Kaplan- Meier method were 88.1 and $96.6 \%$, respectively. A total of 48 patients developed recurrence, and 18 patients had succumbed to RCC at the last follow-up. Among the clinicopathological factors that were assessed by the log-rank test, age ( $>62$ years), pT stage $(\geq$ pT3), Fuhrman grade (3/4), ISUP grade (3/4), the presence of TN and the presence of MVI, were all associated with RFS and CSS on the univariate analysis (Figs. 3 and 4). Using multivariate analysis, we analyzed independent prognostic factors for RFS and CSS for the Fuhrman grade (group Fuhrman) and ISUP grade (group ISUP). The former group, consisting of age, pT stage, Fuhrman grade, TN and MVI, was incorporated into a multivariate analysis using the Cox proportional hazards model. The latter group, consisting of age, pT stage, ISUP grade, TN and MVI, was incorporated into a multivariate 

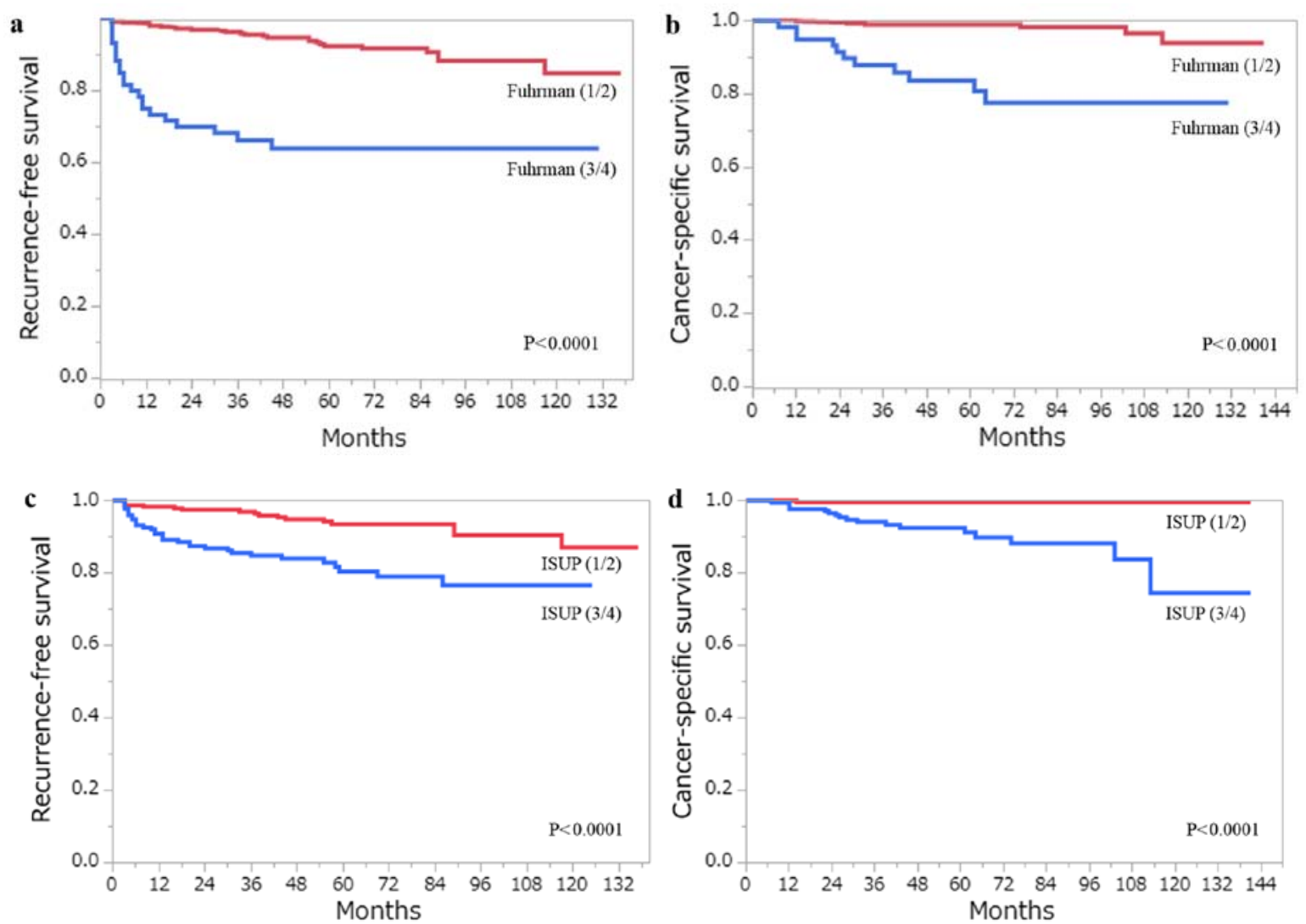

Figure 3. (a) RFS and (b) CSS following curative surgery for tumors classified as Fuhrman grade 1/2 (red line) vs. Fuhrman grade 3/4 (blue line). (c) RFS and (d) CSS following curative surgery for tumors classified as ISUP grade 1/2 (red line) vs. ISUP grade 3/4 (blue line). RFS, recurrence-free survival; CSS, cancer-specific survival; ISUP, International Society of Urological Pathology.
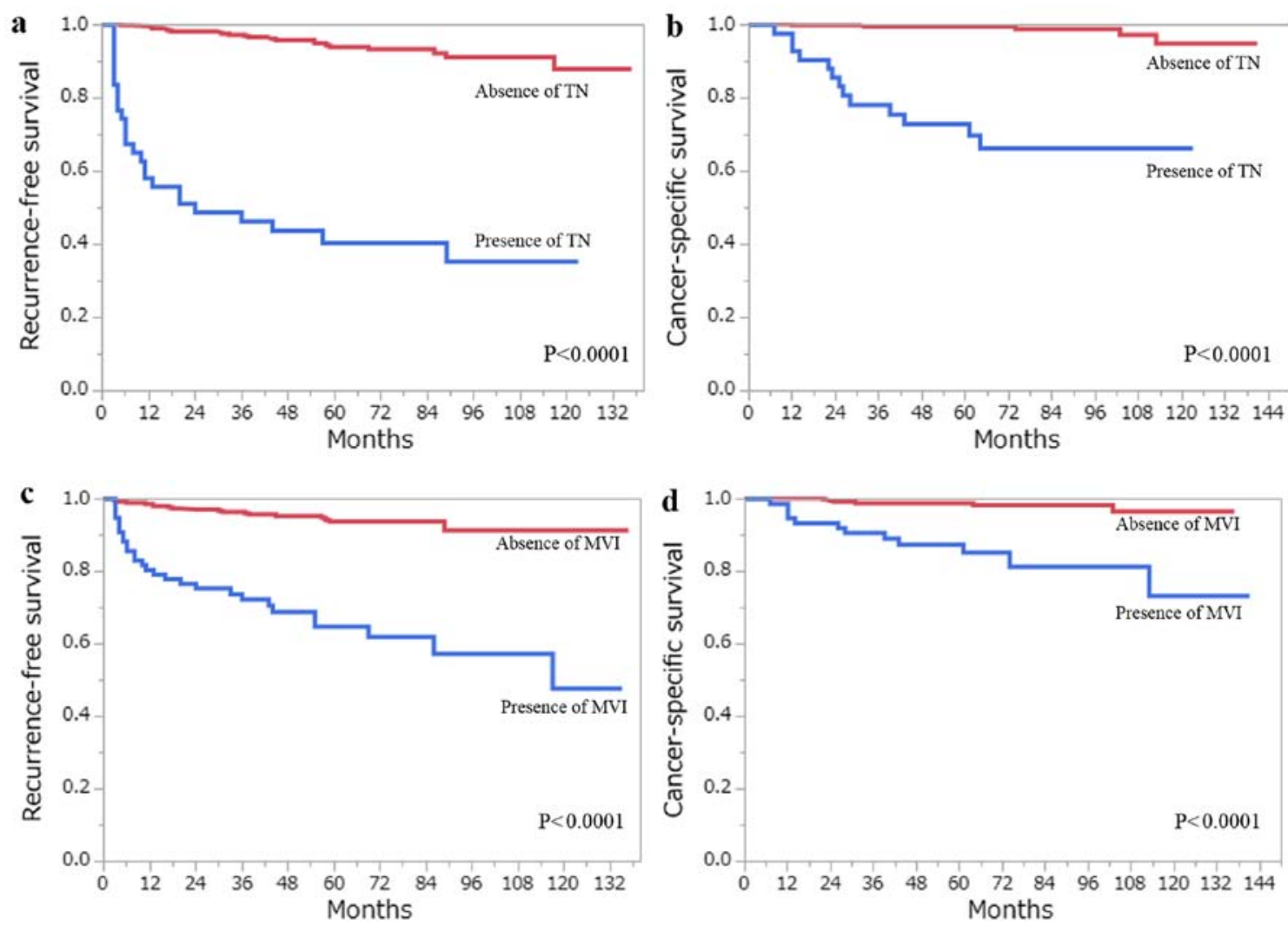

Figure 4. (a) RFS and (b) CSS following curative surgery for tumors without TN (red line) vs. those with TN (blue line). (c) RFS and (d) CSS following curative surgery for tumors without MVI (red line) vs. those with MVI (blue line). RFS, recurrence-free survival; CSS, cancer-specific survival; TN, tumor necrosis; MVI, microvascular invasion. 
Table IV. Risk factors for predicting postoperative recurrence and cancer-specific survival in ccRCC using the Fuhrman grading system.

\begin{tabular}{|c|c|c|c|c|c|c|}
\hline \multirow[b]{3}{*}{ Factors } & \multicolumn{3}{|c|}{ Recurrence-free survival } & \multicolumn{3}{|c|}{ Cancer-specific survival } \\
\hline & \multirow{2}{*}{$\frac{\text { Univariate }}{\text { P-value }}$} & \multicolumn{2}{|c|}{ Multivariate } & \multirow{2}{*}{$\frac{\text { Univariate }}{\text { P-value }}$} & \multicolumn{2}{|c|}{ Multivariate } \\
\hline & & HR $(95 \%$ CI $)$ & P-value & & HR (95\% CI) & P-value \\
\hline $\begin{array}{l}\text { Age (years) } \\
\leq 62\end{array}$ & 0.0246 & & 0.0580 & 0.0018 & & 0.0059 \\
\hline$>62$ & & $1.78(0.99-3.31)$ & & & $4.74(1.51-20.9)$ & \\
\hline $\begin{array}{l}\text { Sex } \\
\text { Female } \\
\text { Male }\end{array}$ & 0.5708 & & & 0.4909 & & \\
\hline $\begin{array}{l}\text { pT stage } \\
\leq \mathrm{pT} 2\end{array}$ & $<0.0001$ & & 0.4687 & $<0.0001$ & & 0.8612 \\
\hline$\geq \mathrm{pT} 3$ & & $1.35(0.61-3.10)$ & & & $1.12(0.33-4.42)$ & \\
\hline $\begin{array}{l}\text { Fuhrman grade } \\
1 / 2\end{array}$ & $<0.0001$ & & 0.1666 & $<0.0001$ & & 0.0497 \\
\hline $3 / 4$ & & $1.62(0.82-3.23)$ & & & $2.97(1.00-9.37)$ & \\
\hline $\begin{array}{l}\mathrm{TN} \\
\text { Absence }\end{array}$ & $<0.0001$ & & $<0.0001$ & $<0.0001$ & & 0.0007 \\
\hline Presence & & $6.62(3.11-13.9)$ & & & $8.90(2.45-34.8)$ & \\
\hline $\begin{array}{l}\text { MVI } \\
\text { Absence }\end{array}$ & $<0.0001$ & & 0.0057 & $<0.0001$ & & 0.2171 \\
\hline Presence & & $2.96(1.34-6.27)$ & & & $2.41(0.58-9.21)$ & \\
\hline
\end{tabular}

ccRCC, clear cell renal cell carcinoma; TN, tumor necrosis; MVI, microvascular invasion; HR, hazard ratio; CI, confidence interval.
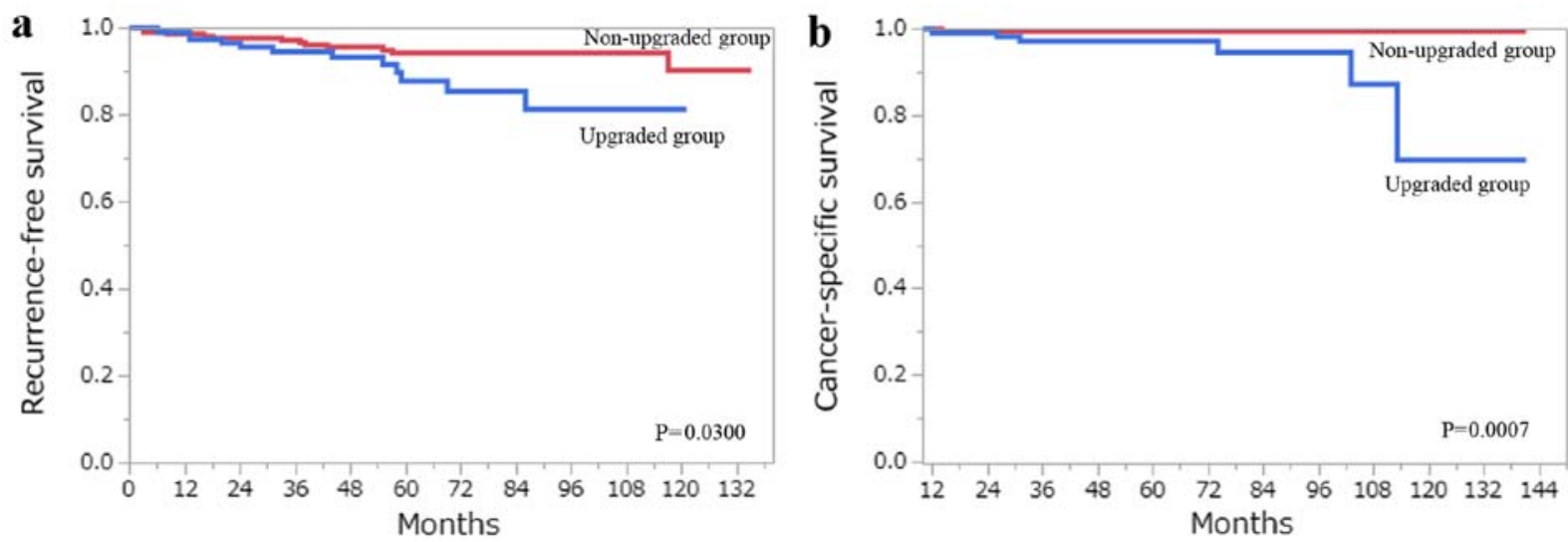

Figure 5. (a) RFS and (b) CSS following curative surgery for tumors classified from Fuhrman grade 2 to ISUP grade 2 (red line) vs. those upgraded from Fuhrman grade 2 to ISUP grade 3 (blue line). RFS, recurrence-free survival; CSS, cancer-specific survival; ISUP, International Society of Urological Pathology.

analysis using the Cox proportional hazards model. In group Fuhrman, TN $(\mathrm{P}<0.0001)$ and MVI $(\mathrm{P}=0.0057)$ were independent risk factors for postoperative recurrence, while age $(\mathrm{P}=0.0059)$, Fuhrman grade $(\mathrm{P}=0.0497)$ and $\mathrm{TN}(\mathrm{P}=0.0007)$ were independent risk factors for CSS (Table IV). In group ISUP, TN $(\mathrm{P}<0.0001)$ and MVI $(\mathrm{P}=0.0057)$ were independent risk factors for postoperative recurrence, while age $(\mathrm{P}=0.0327)$, ISUP grade $(\mathrm{P}=0.0355)$ and $\mathrm{TN}(\mathrm{P}=0.0003)$ were independent risk factors for CSS (Table V). The predictive accuracy for
RFS using group Fuhrman and group ISUP was 0.8637 and 0.8642, respectively, whereas for CSS using group Fuhrman and group ISUP was 0.9366 and 0.9478 , respectively.

Clinical outcomes of ccRCC with Fuhrman grade 2. A total of 343 cases with Fuhrman grade 2 were identified, which accounted for the majority of our study population. The accuracy of the ISUP grading system in predicting clinical outcomes was compared with that of the Fuhrman grading 
Table V. Risk factors for predicting postoperative recurrence and cancer-specific survival in ccRCC using the ISUP grading system.

\begin{tabular}{|c|c|c|c|c|c|c|}
\hline \multirow[b]{3}{*}{ Factors } & \multicolumn{3}{|c|}{ Recurrence-free survival } & \multicolumn{3}{|c|}{ Cancer-specific survival } \\
\hline & \multirow{2}{*}{$\frac{\text { Univariate }}{\text { P-value }}$} & \multicolumn{2}{|c|}{ Multivariate } & \multirow{2}{*}{$\frac{\text { Univariate }}{\text { P-value }}$} & \multicolumn{2}{|c|}{ Multivariate } \\
\hline & & $\mathrm{HR}(95 \% \mathrm{CI})$ & P-value & & $\mathrm{HR}(95 \% \mathrm{CI})$ & P-value \\
\hline $\begin{array}{l}\text { Age (years) } \\
\leq 62\end{array}$ & 0.0246 & & 0.0630 & 0.0018 & & 0.0327 \\
\hline$>62$ & & $1.77(0.98-3.28)$ & & & $3.91(1.27-17.0)$ & \\
\hline $\begin{array}{l}\text { Sex } \\
\text { Female } \\
\text { Male }\end{array}$ & 0.5708 & & & 0.4909 & & \\
\hline $\begin{array}{l}\text { pT stage } \\
\leq \mathrm{pT} 2 \\
\geq \mathrm{pT} 3\end{array}$ & $<0.0001$ & $1.41(0.63-3.26)$ & 0.4095 & $<0.0001$ & $1.09(0.32-4.33)$ & 0.8970 \\
\hline $\begin{array}{l}\text { ISUP grade } \\
\quad 1 / 2\end{array}$ & $<0.0001$ & & 0.8596 & $<0.0001$ & & 0.0355 \\
\hline $3 / 4$ & & $1.07(0.53-2.19)$ & & & $9.31(1.73-172)$ & \\
\hline $\begin{array}{l}\text { TN } \\
\text { Absence } \\
\text { Presence }\end{array}$ & $<0.0001$ & $8.01(3.91-16.5)$ & $<0.0001$ & $<0.0001$ & $8.56(2.80-29.9)$ & 0.0003 \\
\hline $\begin{array}{l}\text { MVI } \\
\text { Absence }\end{array}$ & $<0.0001$ & & 0.0057 & $<0.0001$ & & 0.2185 \\
\hline Presence & & $2.97(1.33-6.30)$ & & & $2.32(0.56-8.67)$ & \\
\hline
\end{tabular}

ccRCC, clear cell renal cell carcinoma; ISUP, International Society of Urological Pathology; TN, tumor necrosis; MVI, microvascular invasion; HR, hazard ratio; CI, confidence interval.

system. On reclassifying the 343 Fuhrman grade 2 cases using the ISUP grading system, 224 were classified as ISUP grade 2, while 117 were upgraded to ISUP grade 3 . The RFS at 10 years was $90.4 \%$ in tumors that were revised from Fuhrman grade 2 to ISUP grade 2 (non-upgraded group), and $81.5 \%$ in the tumors that were upgraded from Fuhrman grade 2 to ISUP grade 3 (upgraded group) (Fig. 5a). The CSS at 10 years was 99.6 and $69.9 \%$ in the non-upgraded and upgraded groups, respectively (Fig. 5b). Multivariate analysis using this cohort demonstrated that upgrading from Fuhrman grade 2 to ISUP grade 3 was an independent predictor of CSS (Table VI).

\section{Discussion}

At the ISUP 2012 Consensus Conference, tumor morphotype, SD, RD, TN, the ISUP grading system and MVI were recommended as potential prognostic factors of RCC. Among the major morphological subtypes, namely ccRCC, papillary RCC and chromophobe RCC, ccRCC accounts for $\sim 60-70 \%$ of malignant kidney epithelial tumors and has the poorest prognosis $(3-5,15)$. Therefore, in the present study, these recommended factors were evaluated with the focus being ccRCC. To evaluate the validity of these factors in Japanese patients with localized ccRCC, 406 ccRCC pathological slides were reviewed and reassigned pT stage, SD, RD, TN, nuclear grade and MVI, according to the 2012 ISUP recommendations and the 2016 WHO classification. For each potential risk factor, postoperative RFS and CSS were calculated by the Kaplan-Meier method; independent associations with RFS and CSS were calculated by the Cox regression analysis. Nuclear grade was classified by the Fuhrman and ISUP grading systems and then RFS and CSS were calculated for each classified group. Multivariate analysis indicated that TN and MVI were significantly associated with RFS, while age, nuclear grade and TN were significantly associated with CSS in both groups Fuhrman and ISUP. The c-index for RFS using group ISUP (c-index, 0.8642 ) indicated that its predictive ability is equivalent to that using group Fuhrman (c-index, 0.8637), whereas there was a possibility that the predictive ability for CSS using group ISUP (c-index, 0.9478) may be superior to that using group Fuhrman (c-index, 0.9366).

In the present study, the presence of $\mathrm{TN}$ affected both RFS and CSS as an independent risk factor. Although a number of studies have reported the correlation of TN with established clinicopathological parameters, such as high $\mathrm{T}$ stage, large tumor size, poor tumor grade, and CSS or overall survival, there are only a few reports on the association of the presence of TN with RFS, particularly in the East Asian 
Table VI. Risk factors for predicting postoperative recurrence and cancer-specific survival in ccRCC with Fuhrman grade 2.

\begin{tabular}{|c|c|c|c|c|c|c|}
\hline \multirow[b]{3}{*}{ Factors } & \multicolumn{3}{|c|}{ Recurrence-free survival } & \multicolumn{3}{|c|}{ Cancer-specific survival } \\
\hline & \multirow{2}{*}{$\frac{\text { Univariate }}{\text { P-value }}$} & \multicolumn{2}{|c|}{ Multivariate } & \multirow{2}{*}{$\frac{\text { Univariate }}{\text { P-value }}$} & \multicolumn{2}{|c|}{ Multivariate } \\
\hline & & $\mathrm{HR}(95 \% \mathrm{CI})$ & P-value & & HR $(95 \% \mathrm{CI})$ & P-value \\
\hline $\begin{array}{l}\text { Age (years) } \\
\leq 62\end{array}$ & 0.2070 & & & 0.0325 & & 0.2167 \\
\hline$>62$ & & & & & $3.45(0.52-67.8)$ & \\
\hline $\begin{array}{l}\text { Sex } \\
\text { Female } \\
\text { Male }\end{array}$ & 0.6169 & & & 0.5200 & & \\
\hline $\begin{array}{l}\text { pT stage } \\
\leq \mathrm{pT} 2\end{array}$ & $<0.0001$ & & 0.0582 & 0.0283 & & 0.1785 \\
\hline$\geq \mathrm{pT} 3$ & & $3.06(0.96-9.55)$ & & & $0.23(0.02-1.94)$ & \\
\hline $\begin{array}{l}\text { Fuhrman grade } 2 \\
\text { Non-upgraded group }\end{array}$ & 0.0300 & & 0.7038 & 0.0007 & & 0.0389 \\
\hline Upgraded group & & $1.19(0.49-2.88)$ & & & $7.20(1.09-143)$ & \\
\hline $\begin{array}{l}\mathrm{TN} \\
\text { Absence }\end{array}$ & $<0.0001$ & & 0.0349 & $<0.0001$ & & 0.0444 \\
\hline Presence & & $3.33(1.09-9.75)$ & & & $7.58(1.06-47.2)$ & \\
\hline $\begin{array}{l}\text { MVI } \\
\text { Absence }\end{array}$ & $<0.0001$ & & 0.0047 & 0.0001 & & 0.0168 \\
\hline Presence & & $4.65(1.63-12.8)$ & & & $9.48(1.54-74.1)$ & \\
\hline
\end{tabular}

ccRCC, clear cell renal cell carcinoma; TN, tumor necrosis; MVI, microvascular invasion; HR, hazard ratio; CI, confidence interval.

population $(3,10,13,16-18)$. In our study population of Japanese patients with localized ccRCC, TN, one of the new potential prognostic factors, was found to be the strongest predictive prognostic factor for both RFS and CSS.

The Fuhrman grading system has been widely adopted worldwide, including Japan; however, certain problems have been identified in the literature, such as the inclusion of various tumor types that differ morphologically and genetically, and poor reproducibility due to multiple parameters, including nuclear size and appearance (19-23). The ISUP grading system assesses only nucleolar prominence, is simple and reproducible, and is correlated with clinical outcome $(14,24)$. In our study cohort, multivariate analysis revealed that the ISUP grade was not significantly associated with RFS, but it was significantly associated with CSS. In particular, cases that were subsequently upgraded to ISUP grade 3 from the Fuhrman grade 2 group exhibited a worse prognosis compared with those in the non-upgraded group. The ISUP grading system was found to be superior to the Fuhrman grading system due to its diagnostic reproducibility and its ability to predict clinical outcomes.

The predictive ability of MVI is controversial. Some reports have shown MVI to be correlated with prognosis; however, others have reported no such correlation (25-30). In the present study, the multivariate analysis demonstrated that MVI was independently associated with RFS of both group Fuhrman and group ISUP.
To the best of our knowledge, this study is the first to prove the correlation between coagulative TN and clinical outcome (RFS and CSS), as well as demonstrate the advantages of the ISUP grading system when compared with Fuhrman grading in Japanese ccRCC patients. Based on the results of our study, as well as the report of the 2012 ISUP Consensus Conference, we recommend closer surveillance or adjuvant therapy for patients with the presence of TN and higher ISUP grade (ISUP grade >3) (6).

The present study is limited by its retrospective design. Another limitation is that the majority of our cases lacked clinical data on risk factors that are considered to be associated with the prognosis of RCC, such as smoking and hypertension. Moreover, some patients dropped out of follow-up shortly after surgery, resulting in loss of prognostic data. In the present study, the unclear histological subtypes were excluded, but we included various stages of ccRCC, which may have resulted in confounding bias. To strengthen the reliability of the results of this study, prospective multicenter studies must be designed to confirm these pathological parameters in a larger population of consecutive patients with RCC.

In conclusion, to the best of our knowledge, this retrospective study is the first to report on a Japanese population with RCC to investigate the correlations between the postoperative prognosis of ccRCC and the pathological parameters recommended by the 2012 ISUP Consensus Conference. Adapting the ISUP recommendations and the 2016 WHO classification for a Japanese ccRCC population is likely to be of value in clinical practice. 


\section{Acknowledgements}

Not applicable.

\section{Funding}

No funding was received.

\section{Availability of data and materials}

The analyzed data sets generated during the study are available from the corresponding author on reasonable request.

\section{Authors' contributions}

$\mathrm{HKi}, \mathrm{CI}$ and TU collected the data and wrote the manuscript. $\mathrm{CI}$ and $\mathrm{HKa}$ reviewed the slides and confirmed the pathological diagnosis. HF and TK analyzed and interpreted the patient data regarding the clinical outcomes. HKo, NN and AM provided the study concept and design, and revised the manuscript. The final version of the manuscript was read and approved by all authors.

\section{Ethics approval and consent to participate}

The postoperative prognostic and clinicopathological data were retrospectively analyzed in accordance with a protocol approved by the Tokai University Institutional Review Board (15R-065).

\section{Consent for publication}

Not applicable.

\section{Competing interests}

The authors declare that they have no competing interests.

\section{References}

1. Ferlay J, Soerjomataram I, Dikshit R, Eser S, Mathers C, Rebelo M, Parkin DM, Forman D and Bray F: Cancer incidence and mortality worldwide: Sources, methods and major patterns in GLOBOCAN 2012. Int J Cancer 136: E359-E386, 2015.

2. Znaor A, Lortet-Tieulent J, Laversanne M, Jemal A and Bray F: International variations and trends in renal cell carcinoma incidence and mortality. Eur Urol 67: 519-530, 2015.

3. Moch H, Gasser T, Amin MB, Torhorst J, Sauter G and Mihatsch MJ: Prognostic utility of the recently recommended histologic classification and revised TNM staging system of renal cell carcinoma: A Swiss experience with 588 tumors. Cancer 89: 604-614, 2000.

4. Amin MB, Amin MB, Tamboli P, Javidan J, Stricker H, de-Peralta Venturina M, Deshpande A and Menon M: Prognostic impact of histologic subtyping of adult renal epithelial neoplasms: An experience of 405 cases. Am J Surg Pathol 26: 281-291, 2002.

5. Ficarra V, Martignoni G, Galfano A, Novara G, Gobbo S, Brunelli M, Pea M, Zattoni F and Artibani W: Prognostic role of the histologic subtypes of renal cell carcinoma after slide revision. Eur Urol 50: 786-793, discussion 793-794, 2006.

6. Delahunt B, Cheville JC, Martignoni G, Humphrey PA, Magi-Galluzzi C, McKenney J, Egevad L, Algaba F, Moch H, Grignon DJ, et al; Members of the ISUP Renal Tumor Panel: The International Society of Urological Pathology (ISUP) grading system for renal cell carcinoma and other prognostic parameters. Am J Surg Pathol 37: 1490-1504, 2013.
7. Lee SE, Byun SS, Oh JK, Lee SC, Chang IH, Choe G and Hong SK: Significance of macroscopic tumor necrosis as a prognostic indicator for renal cell carcinoma. J Urol 176: 1332-1337, discussion 1337-1338, 2006.

8. Katz MD, Serrano MF, Grubb RL III, Skolarus TA, Gao F, Humphrey PA and Kibel AS: Percent microscopic tumor necrosis and survival after curative surgery for renal cell carcinoma. J Urol 183: 909-914, 2010.

9. Frank I, Blute ML, Cheville JC, Lohse CM, Weaver AL and Zincke $\mathrm{H}$ : An outcome prediction model for patients with clear cell renal cell carcinoma treated with radical nephrectomy based on tumor stage, size, grade and necrosis: The SSIGN score. J Urol 168: 2395-2400, 2002.

10. Pichler M, Hutterer GC, Chromecki TF, Jesche J, KampelKettner K, Rehak P, Pummer K and Zigeuner R: Histologic tumor necrosis is an independent prognostic indicator for clear cell and papillary renal cell carcinoma. Am J Clin Pathol 137: 283-289, 2012.

11. Lam JS, Shvarts O, Said JW, Pantuck AJ, Seligson DB, Aldridge ME, Bui MH, Liu X, Horvath S, Figlin RA, et al: Clinicopathologic and molecular correlations of necrosis in the primary tumor of patients with renal cell carcinoma. Cancer 103: 2517-2525, 2005.

12. Sengupta S, Lohse CM, Leibovich BC, Frank I, Thompson RH, Webster WS, Zincke H, Blute ML, Cheville JC and Kwon ED: Histologic coagulative tumor necrosis as a prognostic indicator of renal cell carcinoma aggressiveness. Cancer 104: 511-520, 2005.

13. Ficarra V, Martignoni G, Lohse C, Novara G, Pea M, Cavalleri S and Artibani W: External validation of the Mayo Clinic Stage, Size, Grade and Necrosis (SSIGN) score to predict cancer specific survival using a European series of conventional renal cell carcinoma. J Urol 175: 1235-1239, 2006.

14. Delahunt B, Sika-Paotonu D, Bethwaite PB, William Jordan T, Magi-Galluzzi C, Zhou M, Samaratunga $H$ and Srigley JR: Grading of clear cell renal cell carcinoma should be based on nucleolar prominence. Am J Surg Pathol 35: 1134-1139, 2011.

15. Cheville JC, Lohse CM, Zincke H, Weaver AL and Blute ML: Comparisons of outcome and prognostic features among histologic subtypes of renal cell carcinoma. Am J Surg Pathol 27: $612-624,2003$.

16. Kim H, Cho NH, Kim DS, Kwon YM, Kim EK, Rha SH, Park YW, Shim JW, Lee SS, Lee SN, et al; Genitourinary Pathology Study Group of the Korean Society of Pathologists: Renal cell carcinoma in South Korea: A multicenter study. Hum Pathol 35: 1556-1563, 2004.

17. Thompson RH, Leibovich BC, Lohse CM, Cheville JC, Zincke H, Blute ML and Frank I: Dynamic outcome prediction in patients with clear cell renal cell carcinoma treated with radical nephrectomy: The D-SSIGN score. J Urol 177: 477-480, 2007.

18. Isbarn H, Patard JJ, Lughezzani G, Rioux-Leclercq N, Crépel M, Cindolo L, de la Taille A, Zini L, Villers A, Shariat SF, et al: Limited prognostic value of tumor necrosis in patients with renal cell carcinoma. Urology 75: 1378-1384, 2010.

19. Fuhrman SA, Lasky LC and Limas C: Prognostic significance of morphologic parameters in renal cell carcinoma. Am J Surg Pathol 6: 655-663, 1982.

20. Delahunt B: Advances and controversies in grading and staging of renal cell carcinoma. Mod Pathol 22 (Suppl 2): S24-S36, 2009.

21. Goldstein NS: Grading of renal cell carcinoma. Urol Clin North Am 26: 637-642, vii, 1999.

22. Lang H, Lindner V, de Fromont M, Molinié V, Letourneux H, Meyer N, Martin M and Jacqmin D: Multicenter determination of optimal interobserver agreement using the Fuhrman grading system for renal cell carcinoma: Assessment of 241 patients with > 15-year follow-up. Cancer 103: 625-629, 2005.

23. Lanigan D, Conroy R, Barry-Walsh C, Loftus B, Royston D and Leader M: A comparative analysis of grading systems in renal adenocarcinoma. Histopathology 24: 473-476, 1994.

24. Delahunt B, Bethwaite PB and Nacey JN: Outcome prediction for renal cell carcinoma: Evaluation of prognostic factors for tumours divided according to histological subtype. Pathology 39: 459-465, 2007.

25. Pichler M, Hutterer GC, Chromecki TF, Jesche J, GroseljStrele A, Kampel-Kettner K, Pummer K and Zigeuner R: Prognostic value of the Leibovich prognosis score supplemented by vascular invasion for clear cell renal cell carcinoma. J Urol 187: 834-839, 2012. 
26. Cho HJ, Kim SJ, Ha US, Hong SH, Kim JC, Choi YJ and Hwang TK: Prognostic value of capsular invasion for localized clear-cell renal cell carcinoma. Eur Urol 56: 1006-1012, 2009.

27. Sevinç M, Kirkali Z, Yörükoğlu K, Mungan U and Sade M: Prognostic significance of microvascular invasion in localized renal cell carcinoma. Eur Urol 38: 728-733, 2000.

28. Van Poppel H, Vandendriessche H, Boel K, Mertens V, Goethuys H, Haustermans K, Van Damme B and Baert L: Microscopic vascular invasion is the most relevant prognosticator after radical nephrectomy for clinically nonmetastatic renal cell carcinoma. J Urol 158: 45-49, 1997.

29. Roos FC, Weirich J, Victor A, Elsässer A, Brenner W, Biesterfeld S, Hampel C and Thüroff JW: Impact of several histopathological prognosticators and local tumour extension on oncological outcome in $\mathrm{pT} 3 \mathrm{~b} / \mathrm{c}$ NOM0 renal cell carcinoma. BJU Int 104: 461-469, 2009.
30. Lang H, Lindner V, Letourneux H, Martin M, Saussine C and Jacqmin D: Prognostic value of microscopic venous invasion in renal cell carcinoma: Long-term follow-up. Eur Urol 46: 331-335, 2004.

This work is licensed under a Creative Commons Attribution-NonCommercial-NoDerivatives 4.0 International (CC BY-NC-ND 4.0) License. 